\title{
Association of Serum Sex-Hormone-Binding Globulin in Pregnant Women with Gestational Diabetes Mellitus
}

\author{
Asma Sharmin, ${ }^{1}$ Mohammad Reza Hossain Khan, ${ }^{2}$ Jesmin Jahan, ${ }^{3}$ \\ Md. Shameem, ${ }^{4}$ Shahzadi Afruza, ${ }^{5}$ Summi Leunard Keya ${ }^{6}$
}

\begin{abstract}
Background \& objective: Gestational diabetes mellitus (GDM) is a common pregnancy complication and is associated with increase maternal and neonatal morbidity. Circulating Sex hormone-binding globulin (SHBG) levels are inversely associated with insulin resistance, and insulin resistance is the hallmark of GDM. This study was carried out to investigate SHBG level in pregnancy and to analyze the association of SHBG with GDM.

Materials \& Methods: This case-control study was carried out in the antenatal clinic of the department of obstetrics \& gynecology, BSMMU, Shahbag, Dhaka, over a period of 12 months between August 2017 to July 2018. Participants were 80 in number, aged between 18 to 35 years, having singleton pregnancy with 24 to 28 weeks of gestation. 40 GDM cases were enrolled as the case, and 40 nonGDM cases were enrolled as the control. Pregnant women with overt diabetes/diabetes in pregnancy, previous history of GDM, pre-eclampsia, gestational/chronic hypertension, known case of liver disease, thyroid disorder, acute or chronic renal disease, congenital fetal anomaly, multiple pregnancies, smoking, H/O polycystic ovary syndrome (PCOS) was excluded from the study. Comparison of means made by using Student t-test and categorical data were analyzed by Chi-square Test, and Pearson's correlation was utilized between serum sex-hormone binding globulin level $\mathrm{nmol} / \mathrm{L}$ with fasting plasma glucose $(\mathrm{mmol} / \mathrm{L})$ and 2-hour after $75 \mathrm{~g}$ glucose (mmol/L). Statistical significance was set at $\mathrm{p}<0.05$.

Results: The median value of serum SHBG was $245.0 \mathrm{nmol} / \mathrm{L}(195.8-278.1)$ in the case group and $390.1 \mathrm{nmol} / \mathrm{L}(310.2-465.3)$ in the control group. Women with GDM were found to have significantly lower levels of SHBG compared to the controls $(p<0.05)$. There was a moderate negative significant correlation $(r=-0.621 ; p=0.001)$ between fasting plasma glucose $(\mathrm{mmol})$ with serum SHBG $(\mathrm{nmol} / \mathrm{l})$ in GDM patients. On the other hand, there was a weak negative but not significant correlation $(r=-0.229$; $p=0.155$ ) was found between 2 hours after plasma glucose with serum SHBG in the GDM group.
\end{abstract}

Conclusion: A significantly lower SHBG level is associated with GDM.

Keywords: SHBG, pregnancy, gestational diabetes mellitus

TAJ 2021; 34: No-1: 80-85

\section{Introduction}

Pregnancy is characterized by endocrinologic and metabolic changes to ensure energy and nutrient supply to the fetus. Placental diabetogenic hormones cause insulin resistance and

${ }^{1}$ Medical Officer (Obstetrics and Gynaecology), Department of Obstetrics and Gynaecology, Kurmitola General Hospital, Dhaka Cantonment, Dhaka.

2 Medical Officer (Orthopaedic Surgery), Department of Orthopaedic Surgery, National Institute of Traumatology and Orthopaedic Rehabilitation (NITOR), Dhaka.

3 Junior Consultant (Obstetrics and Gynaecology), Upazila Health Complex,Tongibari, Munshiganj.

${ }^{4}$ Assistant Professor (Neonatology), Department of Pediatrics, Rajshahi Medical College, Rajshahi.

5 Junior Consultant (Obstetrics and Gynaecology), Upazila Health Complex, Bandar, Narayanganj.

${ }^{6}$ Assistant Registrar, Department of Burn and Plastic Surgery, Rajshahi Medical College, Rajshahi. 
hyperinsulinemia, which predispose to diabetes development in pregnancy.

Worldwide approximately $7 \%$ of pregnancies are affected by GDM, ranging from 1-14\%, depending on the population studied and diagnostic criteria employed. The prevalence of GDM varies among different races and ethnic groups. ${ }^{1}$ In Bangladesh, the prevalence of GDM is $9.7 \% .^{2}$

Hyperglycemia first detected at any time during pregnancy is classified as either: Diabetes mellitus in pregnancy (overt diabetes) or gestational diabetes mellitus (GDM). GDM is diagnosed when fasting plasma glucose (FPG) is $5.1-6.9$ $\mathrm{mmol} / \mathrm{L}$ or 2 hours after 75 -gram glucose is 8.5 $11.0 \mathrm{mmol} / \mathrm{L}$, but when FPG is $\geq 7.0 \mathrm{mmol} / \mathrm{L}$ or 2 hours after 75 -gram glucose is $\geq 11.1 \mathrm{mmol} / \mathrm{L}$ or random plasma glucose (RPG) is $\geq 11.0 \mathrm{mmol} / \mathrm{L}$ in the presence of diabetes symptoms, it is labeled as diabetes in pregnancy: ${ }^{3}$

GDM causes adverse maternal and neonatal outcomes, which includes pre-eclampsia, birth trauma, macrosomia, premature birth, neonatal asphyxia, neonatal hypoglycemia, polyhydramnios, and operative delivery. ${ }^{4,5}$

The diagnosis and appropriate treatment of GDM can decrease maternal and fetal complications. ${ }^{6,7}$ Therefore, identifying women with GDM is important to improve maternal and fetal outcomes. Possible association of SHBG with GDM may alert gynecologists to take early measures. According to Kim et al., once diagnosed with GDM, women seemed to progress to type-2 diabetes mellitus (T2DM ), and this progression increased steeply within the first five years after delivery. ${ }^{8} \quad$ Gynecologists could alert GDM patients about this possible adverse outcome.

SHBG is a plasma glycoprotein that is produced by the hepatocytes and has a high affinity for steroid hormones. ${ }^{9}$ Pre-pregnant value of SHBG in females 16.8 - $125.2 \mathrm{nmol} / \mathrm{l}$. During pregnancy, 5 to 10 -fold increase the level of SHBG by the influence of rising levels of estrogen. ${ }^{10}$
Sex hormone-binding globulin (SHBG) secretion is suppressed by insulin, and low levels of SHBG are frequently observed in states of insulin resistance and have been studied as a potential predictor of the development of T2DM. ${ }^{11,12}$ Insulin resistance has been identified as the hallmark of GDM, and therefore, it is etiologically similar to T2DM. ${ }^{13}$ Based on Decheney AH, GDM is considered to be T2DM that is unmasked during pregnancy due to the metabolic changes of pregnancy. ${ }^{13}$ The mechanism by which low SHBG levels reduce insulin sensitivity is still not well documented. SHBG may directly bind to its cellular receptors such as $G$ protein-coupled receptors on the plasma membrane, independent of its binding to androgen in the circulation, and activate adenylyl cyclase, resulting in the production of cyclic adenosine monophosphate and subsequently increased glucose uptake and improved insulin sensitivity. ${ }^{14,15}$ In normal pregnancy, SHBG levels rise progressively until 24 weeks of gestation. ${ }^{16,17}$ Subsequently, the level of SHBG stabilizes, and this may be attributable to the hyperinsulinemia and insulin resistance that increase progressively from the late second trimester. ${ }^{18,19}$

The primary aim of this study was to investigate SHBG levels in pregnancy and subsequently evaluate their possible association with GDM in the study population.

\section{Materials and Methods}

This Case-Control study was carried out in the antenatal clinic of the Department of Obstetrics \& Gynecology, BSMMU, Shahbag, Dhaka, over a period of 12 months between August 2017 to July 2018. Participants were 80 in number, aged between 18 to 35 years, primi or multigravida having singleton pregnancy with 24 to 28 weeks of gestation. $40 \mathrm{GDM}$ cases were enrolled as Cases 40 non GDM cases were enrolled as control. Pregnant women with overt diabetes/diabetes in pregnancy, previous history of GDM, preeclampsia, gestational/chronic hypertension, 
thyroid disorder, acute or chronic renal disease, congenital fetal anomaly, multiple pregnancies, smoking, known case of liver disease, H/O polycystic ovary syndrome (PCOS) was excluded from the study. Determination of pregnancy duration was based on LMP or routine ultrasonographic examination performed in $1^{\text {st }}$ trimester. Comparison of means made by using Student t-test and categorical data were analyzed by Chi-square Test and Pearson's correlation was utilized between serum sex-hormone binding globulin level $\mathrm{nmol} / \mathrm{L}$ with fasting plasma glucose $(\mathrm{mmol} / \mathrm{L})$ and 2 -hour after $75 \mathrm{~g}$ glucose $(\mathrm{mmol} / \mathrm{L})$. Statistical significance was set at $\mathrm{p}<0.05$. The protocol of the study was approved by the ethical review committee of BSMMU.

\section{Results:}

A total of 80 participants fulfilling the selection criteria and consenting to participate in the study were included. The analysis was done for the case $(n=40)$ and control $(n=40)$. GDM patients were included as case, and non-GDM patients were included as a control.

Table I: shows the age of the study patients was 18-35 years, but the bulk of the patient were 26 to 30 years old in both case and control group. $40 \%$ of the case and $57.5 \%$ of the control belongs to this age group. The mean age was 29.0 \pm 4.4 years in the case and $28.5 \pm 3.4$ years. The difference was statistically not significant $(\mathrm{p}>0.05)$ between the two groups.

Table I: Distribution of the study patients by age $(n=80)$

Age (in years)

$18-25$

26-30

31-35

Mean \pm SD

Range(min, max)

ns $=$ not significant

p-value reached from unpaired t-test

\section{Case}

$(n=40)$

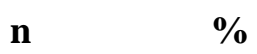

9

16

15

$29.0 \pm 4.4$

18,35

37.5

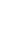

$\%$

\section{5}

$$
40.0
$$

22,35

\section{Control}

$(n=40)$

P value

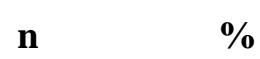

$8 \quad 20.0$

$23 \quad 57.5$

$9 \quad 22.5$

$28.5 \pm 3.4$

$0.571^{\mathrm{ns}}$

Table II shows the median serum SHBG was 245.0 (195.8-278.1) nmol/L in the case and 390.1(310.2465.3) nmol/L in control. The difference was statistically significant $(\mathrm{p}<0.05)$ between the two groups.

Table II: Median value of serum SHBG concentration in study subjects $(n=80)$

$\begin{array}{ccc}\begin{array}{c}\text { Case } \\ (\mathbf{n = 4 0})\end{array} & \begin{array}{c}\text { Control } \\ (\mathbf{n = 4 0})\end{array} & \text { P-value } \\ \text { Median (IQR) } & \text { Median (IQR) } & \\ 245.0(195.8-278.1) & 390.1(310.2-465.3) & 0.001^{\mathrm{s}}\end{array}$

Serum SHBG (nmol/L)

* Mann Whitney $\mathrm{U}$ test is done to measure the level of significance $\mathrm{s}$ $\mathrm{s}=$ significant 
Figure 1: Scatter diagram showing moderate negative significant Pearson's correlation $(r=-0.621$; p=0.001) between Serum SHBG (nmol/L) and Fasting Plasma glucose $(\mathrm{mmol} / \mathrm{L})$ in GDM.

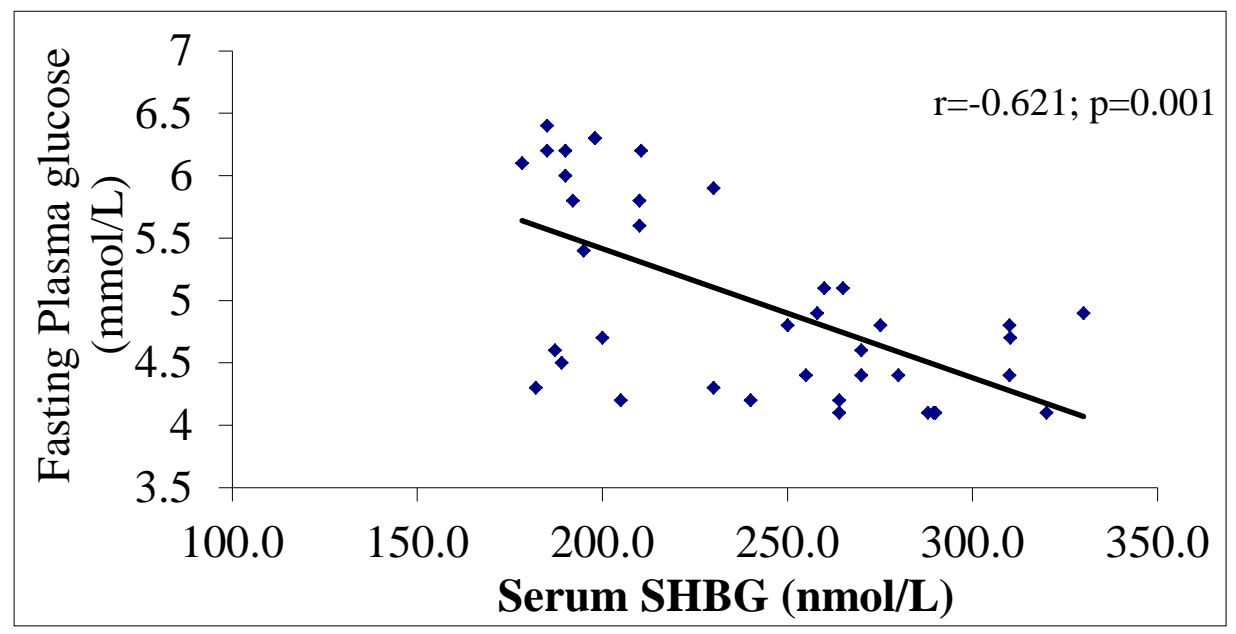

Figure 2: Scatter diagram showing weak negative not significant Pearson's correlation $(r=-0.229$; $\mathrm{p}=0.155)$ between Serum SHBG (nmo/l) and 2-hour after plasma glucose in GDM.

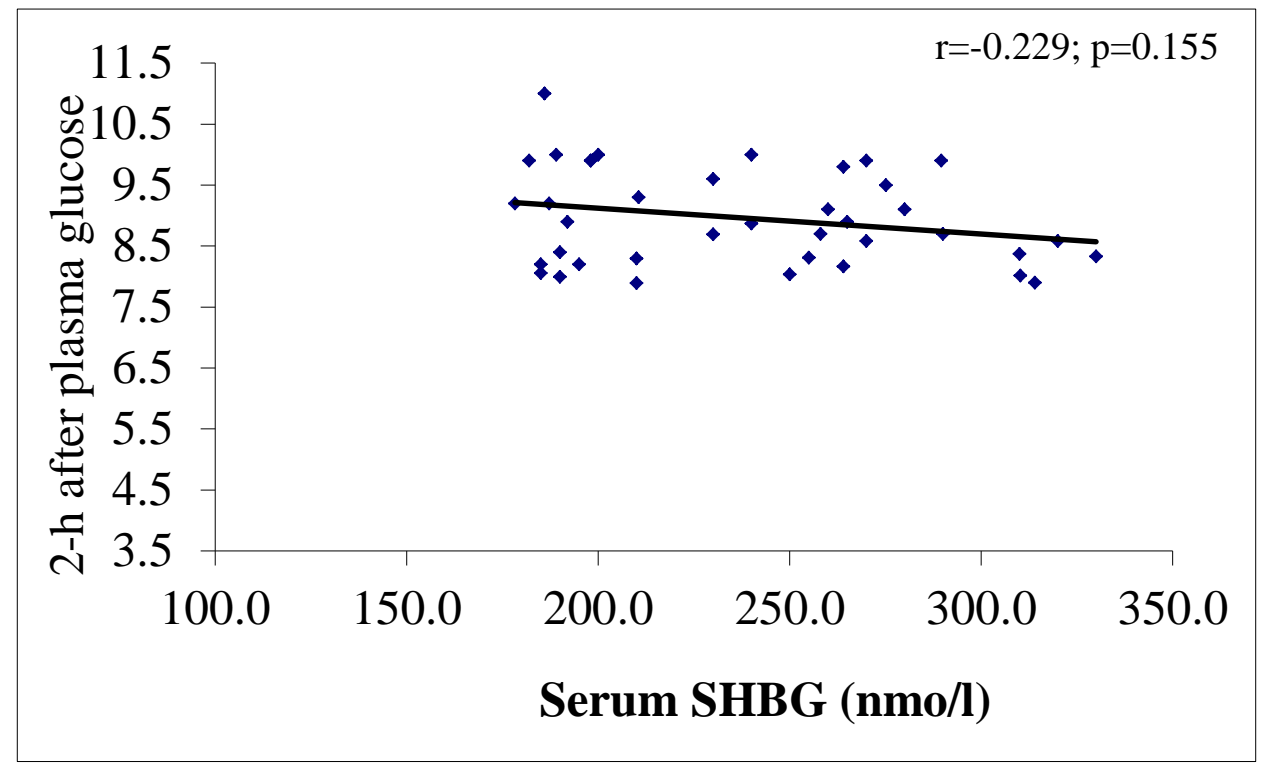





\section{Discussion}

In this present study, it was observed that the mean age was 29.0 \pm 4.4 years in the case and $28.5 \pm 3.4$ years in the control. The difference was statistically not significant $(\mathrm{p}>0.05)$ between the two groups. Tawfeek et al. found the mean age was 29.27 \pm 6.87 years in GDM and 26.84 \pm 6.99 years in non-GDM. The difference was also statistically not significant $(\mathrm{p}>0.05)$ between the two groups. ${ }^{17}$ Anderson and Zhiqun observed that the mean age of the women in the control group was $26.89 \pm 3.14$ years versus the mean age of $29.63 \pm 4.93$ years in cases. $^{21}$ Almost similar observations regarding the mean age distribution were observed by Caglar et al., Jin et al., VeltmanVerhulst et al..$^{22,23,24}$ The difference in mean age and age range may be due to geographical, racial, and genetic variations causes in different studies.

In this current study, the median value of serum SHBG was $245.0 \mathrm{nmol} / \mathrm{L}(195.8-278.1)$ in the case and $390.1 \mathrm{nmol} / \mathrm{L}(310.2-465.3)$ in the control. The difference between the two means was found to be statistically significant. Similar observations regarding the SHBG levels were found by Nanda et $\mathrm{al}^{25}$. They found it significantly lower in the GDM group in which the median was 224.5 $\mathrm{nmol} / \mathrm{l}$ (166.2-283.8) and 295.9nmol/1 (233.0$370.3)$ in the control group. In Anderson and Zhiqun study, SHBG levels were found to be significantly lower in the GDM group than in the control group. SHBG concentration in the GDM group was $53.64 \pm 31.91 \mathrm{nmol} / \mathrm{l}$, while in the control group was $71.33 \pm 30.58 \mathrm{nmol} / \mathrm{l}^{21}$ Similarly, Tawfeek et al. found women with GDM had significantly lower levels of SHBG concentrations compared to non GDM women at 24-28 weeks of pregnancy, median $23 \mathrm{nmol} / \mathrm{l}(18$ $30)$ in the case and $78 \mathrm{nmol} / \mathrm{l}(65-96)$ in control, $\mathrm{p}<0.001 .^{20}$ The present study findings are higher but consistent with these results. Kopp et al. found that SHBG level $512 \pm 249 \mathrm{nmol} / \mathrm{l}$ vs. $643 \pm 137$ $\mathrm{nmol} / \mathrm{l}, \quad \mathrm{p}<0.001 .{ }^{26}$ Many investigators also reported that SHBG levels had been shown to be consistently lower women with GDM. ${ }^{27,28}$ Those findings are also consistent with the present study.

In this current study, it was observed that there was a moderate negative significant correlation $(\mathrm{r}=-0.621 ; \mathrm{p}=0.001)$ between fasting plasma glucose (mmol) with serum SHBG (nmol/l) in GDM patients. However, there was a weak negative, but not significant correlation $(\mathrm{r}=-0.229$; $\mathrm{p}=0.155$ ) was found between 2-hour after plasma glucose with Serum SHBG in GDM patients. Kim et al. In a cross-sectional study of SHBG with glucose among women with recent GDM found at baseline, lower SHBG levels were associated with higher FPG but no significant association with the 2hours glucose. ${ }^{29}$ Kim's findings are consistent with our study. But a different finding was observed by Kopp et al. They found that SHBG was inversely correlated with 1 hour $(r=-0.20$; $\mathrm{p}<0.5)$ and 2 hours blood glucose level $(\mathrm{r}=-0.30$; $\mathrm{p}<0.01) .{ }^{26}$

\section{Conclusion:}

Women with GDM have significantly lower serum SHBG compared to non GDM women. Low serum SHBG is associated with GDM.

\section{References}

1. Murphy A, Janzen C, Strehlow SL, Greenspoon JS, Palmer SM. 2013. Diabetes Mellitus and Pregnancy. Current diagnosis and treatment, Obstetrics and Gynecology, $11^{\text {th }}$ ed. McGraw-Hill Companies, 2013; 31:509-418.

2. Jesmin S, Akter S, Akashi $\mathrm{H}$, et al. Screening for gestational diabetes mellitus and its prevalence in Bangladesh. Diabetes Res Clin Pract 2014; 103(1):57-62.

3. Diagnostic criteria and classification of hyperglycaemia first detected in pregnancy. Geneva: World Health Organization; 2013.

4. Ferrara A, Weiss NS, Hedderson MM, et al. Pregnancy plasma glucose levels exceeding the American Diabetes Association thresholds, but below the National Diabetes Data Group thresholds for gestational diabetes mellitus, are related to the risk of neonatal macrosomia, hypoglycaemia and hyperbilirubinaemia. Diabetologia. 2007; 50(2):298306.

5. Jin Z, Chi XS, Teng WP, et al. Sex hormonebinding globulin of gestational diabetes mellitus pregnant women with well-controlled glucose and pregnancy outcomes. Zhonghua $\mathrm{Fu}$ Chan $\mathrm{Ke} \mathrm{Za}$ Zhi. 2011; 46(6):422-26.

6. Crowther CA, Hiller JE, Moss JR, McPhee AJ, Jeffries WS, Robinson. Australian Carbohydrate Intolerance Study in Pregnant Women (ACHOIS) Trial Group. Effect of treatment of gestational diabetes mellitus on pregnancy outcomes. N Engl J Med 2005; 352(24):2477-86. 
7. Kim C, Newton KM, Knopp RH. Gestational diabetes and the incidence of type 2 diabetes: a systematic review. Diabetes Care 2002; 25(10):21862-8.

8. Langer $\mathrm{O}$, Yogev $\mathrm{Y}$, Most $\mathrm{O}$, Xenakis EMJ. Gestational diabetes: The consequences of not treating . Amer J Ob-Gyn 2005; 192(4):989-97.

9. Anderson DC. Sex-hormone-binding globulin. Clin Endocrinol 1974; 3(1):69-96.

10. Puget M, Nader N, Hogeveen K, Raverot G, Déchaud $H$, Grenot C. Sex hormone-binding globulin gene expression in the liver: drugs and the metabolic syndrome. Mol Cell Endocrinol 2010; 316(1):53-9.

11. Le TN, Nestler JE, Strauss JF 3rd, Wickham EP 3rd. Sex hormone-binding globulin and type 2 diabetes mellitus. Trends Endocrinol Metab 2012; 23(1):32-40.

12. Ding EL, Song Y, Manson JE, et al. Sex hormonebinding globulin and risk of type 2 diabetes in women and men. $N$ Engl $J$ Med 2009; 361(12):1152-63.

13. Decherney $A H$, Nathan L, Laufer $N$, Roman $A S$. Current Diagnosis and Treatment: Obstetrics and Gynecology, $11^{\text {th }}$ ed. McGraw Hill: Lange, 2013.

14. Nakhla AM, Leonard J, Hryb DJ, Rosner W. Sex hormone-binding globulin receptor signal transduction proceeds via a $G$ protein. Steroids 1999; 64(3):213-6.

15. Heinlein $C A$, Chang $C$. The roles of androgen receptors and androgen-binding proteins in nongenomic androgen actions. Mol Endocrinol 2002; 16(10):2181-7.

16. Kerlan V, Nahoul K, Le Martelot MT, Bercovici JP. Longitudinal study of maternal plasma bioavailable testosterone and androstanediol glucuronide levels during pregnancy. Clin Endocrinol 1994; 40(2):2637.

17. O'Leary P, Boyne P, Flett P, Beilby J, James I. Longitudinal assessment of changes in reproductive hormones during normal pregnancy. Clin Chem 1991; 37(5):667-72.

18. Catalano PM, Tyzbir ED, Roman NM, Amini SB, Sims EA. Longitudinal changes in insulin release and insulin resistance in nonobese pregnant women. Am J Obstet Gynecol 1991; 165(6):1667-72.

19. Stanley K, Fraser R, Bruce C. Physiological changes in insulin resistance in human pregnancy: longitudinal study with the hyperinsulinaemic euglycaemic clamp technique. $\mathrm{Br} \mathrm{J}$ Obstet Gynaecol. 1998; 105(7):756-9.

20. Tawfeek MA, Alfadhli EM, Alayoubi AM, EIBeshbishy HA, Habib FA. Sex hormone-binding globulin as a valuable biochemical marker in predicting gestational diabetes mellitus. BMC women's health 2017; 17(1):18.

21. Anderson S. Zhiqun Z. 2015. Sex hormone-binding globulin in gestational diabetes mellitus. Med $\mathrm{J}$ Obstet Gynecol 2015; 3(2):1057.

22. Caglar GS, Ozdemir ED, Cengiz SD, Demirtaş S. Sex-hormone-binding globulin early in pregnancy for the prediction of severe gestational diabetes mellitus and related complications. J Obstet Gynaecol Res 2012; 38(11):1286-93.

23. Jin Z, Guan X, Gao H, et al.. The change in sex hormone-binding globulin and the influence by gestational diabetes mellitus in fetal period. Gynecol Endocrinol 2009; 25 (10):647-52.

24. Veltman-Verhulst SM, van Haeften TW, Eijkemans MJ, de Valk HW, Fauser BC, Goverde AJ. Sex hormone-binding globulin concentrations before conception as a predictor for gestational diabetes in women with polycystic ovary syndrome. Hum Reprod 2010; 25 (12):3123-8.

25. Nanda S, Savvidou M, Syngelaki A, Akolekar R, Nicolaides $\mathrm{KH}$. Prediction of gestational diabetes mellitus by maternal factors and biomarkers at 11 to 13 weeks. Prenat Diagn 2011; 31(2):135-41.

26. Goto A, Morita A, Goto M, et al. Associations of sex hormone-binding globulin and testosterone with diabetes among men and women (the Saku Diabetes study): a case-control study. Cardiovasc Diabetol 2012; 11:130.

27. Kopp HP, Festa A, Krugluger W, Schernthaner G. Low levels of Sex-Hormone-Binding Globulin predict insulin requirement in patients with gestational diabetes mellitus. Exp Clin Endocrinol Diabetes 2001; 109(7):365-9.

28. Hedderson MM, $X u F$, Darbinian JA, et al.Prepregnancy SHBG concentrations and risk for subsequently developing gestational diabetes mellitus. Diabetes Care 2014; 37(5):1296-303.

29. Kim C, Sen A, Osborne E, Lee JM, Richardson CR. Associations between glucose tolerance and sex hormone-binding globulin among women with recent gestational diabetes mellitus. Diabetes Res Clin Pract 2011; 93(3):e110-2.

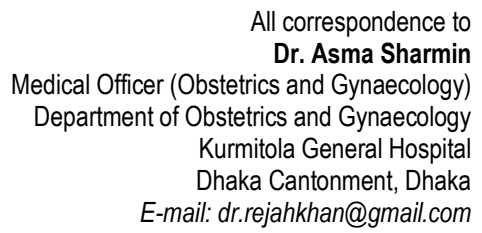

